\title{
Klasifikasi Bahasa Isyarat Indonesia Berbasis Sinyal EMG Menggunakan Fitur Time Domain (MAV, RMS, VAR, SSI)
}

\author{
Ifut Rahayuningsih, Adhi Dharma Wibawa, Eko Pramunanto \\ Departemen Teknik Komputer, Fakultas Teknologi Elektro, Institut Teknologi Sepuluh Nopember (ITS) \\ E-mail: ifut25@gmail.com,wibawa.adhi@yahoo.co.id,ekopram@te.its.ac.id
}

\begin{abstract}
Abstrak-Penggunaan kamera yang dipakai sebagai input media bantu untuk pengenalan bahasa isyarat masih bergantung pada kondisi lingkungan. Sinyal EMG merupakan sinyal yang berasal dari pembacaan aktivitas otot tangan, sehingga sinyal EMG tidak bergantung pada kondisi lingkungan. Oleh karena itu sinyal EMG dapat dimanfaatkan untuk mengenali gerakan bahasa isyarat. Agar dapat digunakan untuk mengenali sebuah gerakan, komputer memerlukan sebuah mekanisme standar dan logis. Permasalah utama yang terjadi dalam pengenalan gerakan adalah bagaimana cara menghasilkan data yang representatif dan konsisten terhadap sampel gerakan. Sinyal EMG hasil perekaman akan dilakukan proses ekstraksi fitur berdasarkan time domain feature dengan metode MAV, RMS, VAR dan SS I. Hasil ekstraksi fitur tersebut akan digunakan sebagai input klasifikasi menggunakan metode naive bayes. Gerakan bahasa isyarat yang dikenali pada penelitian ini ada 20 gerakan. Hasil akurasi pengenalan gerakan antara data training diujikan terhadap data baru dengan perbandingan data 50:50 yaitu sebesar 79\%. Jumlah perbandingan data training yang optimal digunakan untuk pengenalan 20 gerakan Bahasa isyarat Indonesia adalah $\geq \mathbf{5 0 \%}$ dari total data sampel dimana berada pada rata-rata $80 \%$.
\end{abstract}

Kata Kunci-Bahasa Isyarat, Electromyography, Time Domain Features

\section{PENDAHULUAN}

$\mathrm{D}$ ALAM berkomunikasi sehari-hari orang difabel sangat bergantung pada penggunaan bahasa isyarat. Salah satu cara yang berhasil diterapkan untuk mengenali bahasa isyarat yaitu menggunakan teknik computer vision [1] dimana teknik ini menggunakan bantuan kamera untuk menangkap gerakan bahasa isyarat kemudian menggunakannya sebagai input. Kelemahan dari teknik ini adalah masukan yang diberikan sangat bergantung pada kondisi lingkungan terutama pada intensitas cahaya di sekitar. Kondisi pencahayaan di dalamatau di luar ruangan sering berubah-ubah, sehingga kamera akan sulit menangkap gerakan tersebut.

Myo armband merupakan alat yang mampu menangkap gerakan tangan yang bekerja berdasarkan prinsip electromyograph (EMG) yaitu mengambil gerakan berdasarkan aktivitas otot tangan ketika sedang berkontraksi dan relaksasi. Karena sinyal EMG merupakan hasil dari pembacaan aktivitas otot maka sinyal EMG tidak berpengaruh pada kondisi lingkungan. Kelebihan dari myo armband adalah mampu membaca aktivitas kecil seperti pada gerakan jari dimana gerakan tersebut tidak bisa dibedakan oleh kamera.

Pengenalan gerakan oleh komputer berbeda dengan pengenalan gerakan pada mata manusia. Agar komputer dapat digunakan untuk mengenali sebuah gerakan, maka komputer memerlukan sebuah mekanisme standar dan logis. Untuk mendapatkan data yang akurat dan konsisten dari setiap sampel, diperlukan suatu metode ekstraksi fitur. Fitur digunakan sebagai pembeda suatu gerakan dengan gerakan lainnya. Suatu fitur dapat dikatakan bagus apabila fitur tersebut memiliki tingkat pembeda yang tinggi. Hal ini menjadi perhatian karena sebagian besar tingkat keberhasilan klasifikasi dipengaruhi oleh data input yaitu berupa fitur. Dalam analis is sinyal EMG, pengambilan fitur dapat dilakukan dalam beberapa domain, yaitu time domain features, frequency domain features dan time-frequency domain features. Fitur yang sering digunakan dalam klasifikasi sinyal EMG biasanya berada dalam domain waktu, dimana fitur ini lebih cepat dalam hal kalkulasi karena tidak membutuhkan transformasi matematis. Oleh sebab itu, diperlukan penelitian dalam rangka mengetahui tingkat keberhasilan fitur time domain yang diterapkan untuk klasifikasi gerakan bahasa is yarat.

\section{TEORI DASAR}

\section{A. Bahasa Isyarat}

Karakteristik bahasa isyarat adalah memiliki bentuk tangan dan pergerakan lengan yang berbeda-beda pada setiap isyarat kata. Gerakan bahasa isyarat dibedakan menjadi dua, yaitu gerakan statis dan gerakan dinamis. Gerakan statis merupakan gerakan bahasa isyarat yang tidak melibatkan perubahan bentuk tangan atau pergerakan lengan. Sedangkan gerakan dinamis adalah gerakan bahasa isyarat yang melibatkan perubahan bentuk tangan atau pergerakan lengan. Perbedaan gerakan statis dan dinamis terlihat pada Gambar1.

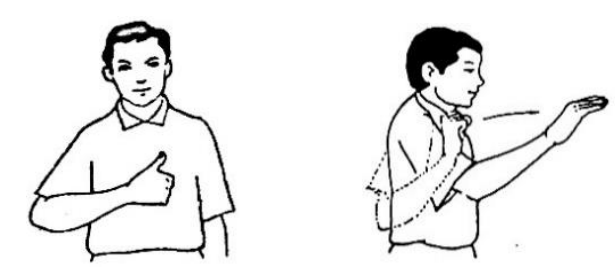


(a)

(b)

Gambar 1. Gerakan statis (a) 'baik', dinamis (b) 'lempar'

\section{B. Electromyography}

Electromyography (EMG) merupakan teknik untuk membaca dan memantau aktivitas sinyal bioelektrik yang diproduksi oleh otot skeletal. Alat yang digunakan untuk merekam sinyal otot tersebut dinamakan electromyograph. Electromyograph akan mendeteksi potensi aktivitas sinyal elektrik dari serabut otot ketika sedang terjadi aktivitas elektrik (kontraksi). Ada beberapa teknik untuk mengukur sinyal EMG, salah satunya adalah menggunakan surface EMG. Myo armband merupakan salah satu alat yang dapat digunakan untuk mengukur sinyal EMG yang menggunakan elektrode jenis permukaan (surface electrode).

Myo amrband merupakan wearable device yang dikembangkan oleh Thalmic Labs yang menggunakan sensor EMG dan mengkombinasikan dengan sensor IMU (Inertial Measurement Unit) meliputi giroskop, akselerometer dan magnetometer untuk mengenali gerakan. Tampilan myo armband terlihat seperti Gambar 2. Sensor IMU dimanfaatkan sebagai tracking motion dan sensor EMG dimanfaatkan untuk muscle sensing. Ada dua jenis data keluaran dari myo armband yaitu data spasial dan data gestural. Data spasial merupakan data yang dihasilkan oleh sensor IMU yang berisi informasi mengenai posisi relatif, kecepatan dan akselerasi dari gerakan motor. Sedangkan data gestural adalah data yang dihasilkan oleh sinyal EMG yang berisi informasi mengenai gerakan tangan yang dilakukan pengguna, misalkan gerakan menggenggam, menekuk, dll. Secara default sampling rate sensor EMG pada myo armband adalah $200 \mathrm{~Hz}$ dan $50 \mathrm{~Hz}$ pada sensor IMU.

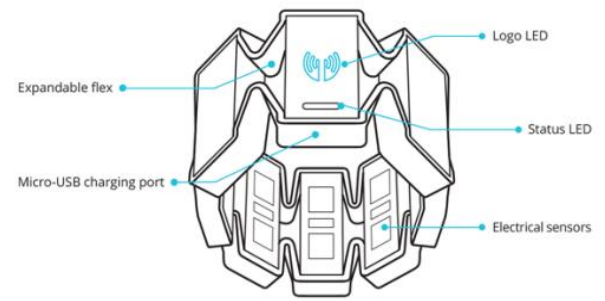

Gambar 2. Myo Armband [1]

Myo Armband mampu membedakan perbedaan gerakan jari dan arah putaran tangan dengan cara mengukur perbedaan pola impuls listrik yang dihasilkan oleh gerakan tangan menggunakan inertial sensor. Myo armband banyak digunakan untuk kontrol game, musik, drone, presentasi dan kontrol multimedia lainnya.

Pengambilan sinyal EMG menggunakan myo armband diletakkan pada otot lengan bawah. Hal ini bertujuan untuk mendapatkan perbedaan yang signifikan ketika tangan sedang melakukan gerakan. Myo armband tidak mendukung pembacaan sinyal pada otot kaki. Pengguna dapat memposisikan myo armband pada kaki, namun data yang dihasilkan hanya berupa data spasial yang berasal dari sensor IMU saja. Elektrode myo armband diposisikan secara circular seperti Gambar 3. Konfigurasi elektrode myo yaitu channel 4 yang memiliki marker biru diikuti channel 3 searah jarum jam dan channel 5 berlawanan arah jarum jam. Otot utama yang dicakup adalah otot Extensor Digitorum dan Flexor Digitorum. Otot tersebut adalah otot yang menggerakkan pergelangan tangan, jari telunjuk, jari tengah, jari manis dan kelingking.

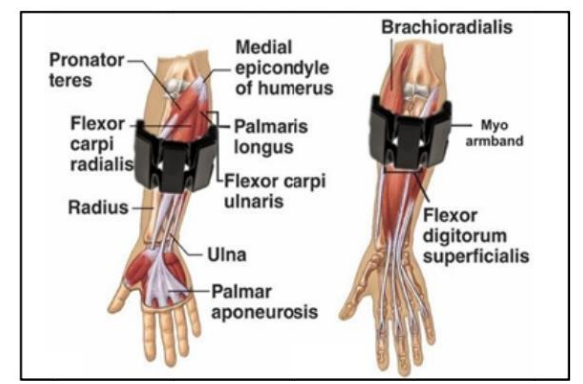

Gambar 3. Otot lengan bawah pada Myo Armband [2]

\section{Time Domain}

Dalam analisis sinyal EMG, ada beberapa metode yang dapat digunakan sebagai pengambilan fitur, yaitu: time domain features, frequency domain features dan time-frequency domain features. Fitur yang sering digunakan dalam klasifikasi sinyal EMG adalah time domain features (TD). Keuntungan menggunakan TD adalah TD lebih cepat untuk dikalkulasi karena TD tidak membutuhkan transformasi matematis. Fiturfitur TD yang digunakan, sebagai berikut:

1) Mean Absolute Value (MAV): digunakan sebagai indeks deteksi onset khususnya dalam sinyal surface EMG untuk control kaki palsu [3]. MAV dapat dihitung menggunakan persamaan (1)

$$
M A V=\frac{1}{N} \sum_{i=1}^{N}\left|x_{i}\right|
$$

2) Root Mean Square (RMS): merupakan berhubungan dengan gaya konstan dan kontraksi nonfatiguing [5]. Persamaan RMS dapat dilihat pada persamaan (2)

$$
R M S=\sqrt{\frac{1}{N} \sum_{i=1}^{N} x_{i}^{2}}
$$

3) Simple Square Integral SSI): parameter ini didefinisikan sebagai sebuah indeks energi [3], yang nilainya dapat dihitung menggunakan persamaan (3)

$$
S S I=\sum_{i=1}^{N} x_{i}^{2}
$$

4) Variance of $E M G$ (VAR): adalah indeks daya $y$ :

Dapat dihitung menggunakan persamaan (4)

$$
V A R=\frac{1}{N-1} \sum_{i=1}^{N} x_{i}^{2}
$$

\section{Nä̈ve Bayes Classifier}

Metode naive bayes merupakan metode yang digunakan untuk memprediski probabilitas. Sedangkan klasifikasi Bayes adalah klasifikasi statistik yang dapat memprediksi kelas suatu anggota probabilitas. Konsep klasifikasi Naive Bayes atau yang biasa disebut Naive Bayes Classifier diasumsikan bahwa pengklasifikasiannya berdasarkan efek dari suatu nilai atribut sebuah kelas sedangkan atribut yang diberikan adalah bebas dari atribut-atribut lain atau bersifat independen. Naive Bayes Classifier merupakan metode klasifikasi yang berakar dari 
teorema Bayes. Ciri utama dari metode ini adalah asumsi yang sangat kuat (naif) akan independensi dari masing-masing kondisi/kejadian, dimana diasumsikan bahwa setiap atribut contoh (data sampel) bersifat saling lepas satu sama lain berdasarkan atribut kelas. Persamaan naüve bayes dapat dirumuskan sebagai:

$$
P\left(C_{k} \mid x\right)=\frac{P\left(C_{k}\right) P\left(x \mid C_{k}\right)}{P(x)}
$$

Dimana $x$ adalah vector dari fitur dan $C_{k}$ adalah probabilitas kelas $k$. Persamaan tersebut dapat ditulis secara sederhana:

posterior $=\frac{\text { prior } \mathrm{x} \text { likehood }}{\text { evidence }}$

Diasumsikan bahwa independensidiformulasikan sebagai:

$$
P\left(x_{i} \mid C_{k}, x_{1}, \ldots, x_{i-1}, x_{i+1}, \ldots, x_{n}\right)=P\left(x_{i} \mid C_{k}\right)
$$

Kemudian untuk semua $i$, dapat disederhanakan menjadi:

$P\left(C_{k} \mid x_{1}, \ldots, x_{n}\right)=\frac{P\left(C_{k}\right) \prod_{i=1}^{n} P\left(x_{i} \mid C_{k}\right)}{P\left(x_{1}, \ldots, x_{n}\right)}$

Dengan $P\left(x_{1}, \ldots, x_{n}\right)$ adalah konstan maka dapat $P\left(C_{k}\right)$ dan $P\left(x \mid C_{k}\right)$ dapat diestimasikan menggunakan Maximum $A$ Posteriori atau MAP. Penyederhanaan MAP inilah yang disebut nä̈ve bayes. Pada penelitian ini digunakan algoritma Gaussian dengan asumsi bahwa penyebaran data terdistribusi normal. Langkah pertama adalah dengan menghitung nilai mean dan variance setiap fitur. Setelah mendapatkan nilai parameter tersebut maka dilakukan perhitungan prediksi dengan fungsi densitas Gaussian.

\section{METODOLOGI}

Adapun metodologi yang dilakukan pada penelitian ini adalah:

\section{A. Pengambilan Data}

Jumlah responden yang digunakan sebagai subjek penelitian berjumlah satu orang. Gerakan yang dilakukan pada penelitian ini adalah 20 jenis gerakan yang diambil dari Sistem Isyarat Bahasa Indonesia. Responden melakukan 20 kali gerakan untuk satu jenis gerakan. Lama waktu pengambilan data untuk setiap sampel gerakan yaitu sekitar 5 detik. Sinyal EMG diambil menggunakan alat bernama myo armband yang diposisikan pada otot lengan bawah. Pada saat pemasangan myo armband pada otot lengan bawah, perlu diperhatikan tata letaknya sesuai otot yang diteliti. Hal ini perlu dilakukan untuk mengurangi noise sinyal EMG dari otot yang tidak diingikan. Gerakan direkam demgan urutan start - gesture - end yang dapat diamati pada Gambar 4.

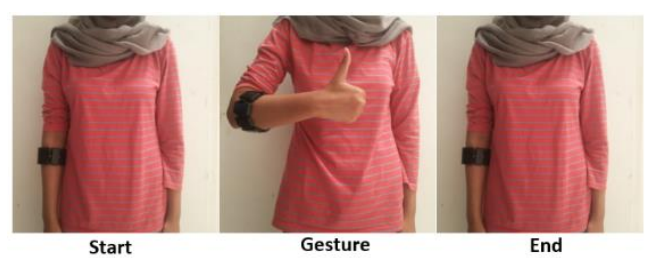

Gambar 4.Urutan perekaman gerakan

Kondisi start dan end adalah sama yaitu dalam posisi istirahat. Gesture merupakan gerakan dasar dari suatu isyarat kata. Setiap melakukan gerakan dimulai dari start hingga end kemudian data disimpan ke dalam file CSV. Pengambilan gerakan baru dimulai dari kondisi start kembali hingga gerakan end dan akan disimpan sebagai file CSV baru. Data gerakan tersebut kemudian dikirim ke PC melalui koneksi Bluetooth.

Sinyal EMG yang diperoleh pada saat perekaman berasal dari keseluruhan area yang diberikan elektrode. Sebab proses kontraksi dan relaksasi titap-tiap otot gerak pada area tertentu tidak bersamaan, maka sinyal yang ditangkap berbentuk sinyal acak. Hal ini mengakibatkan pola sinyal setiap channel tidak sama saat melakukan suatu gerakan. Sinyal yang tinggi menunjukkan adanya aktivitas kontraksi otot seperti yang ditunjukkan pada Gambar 5.

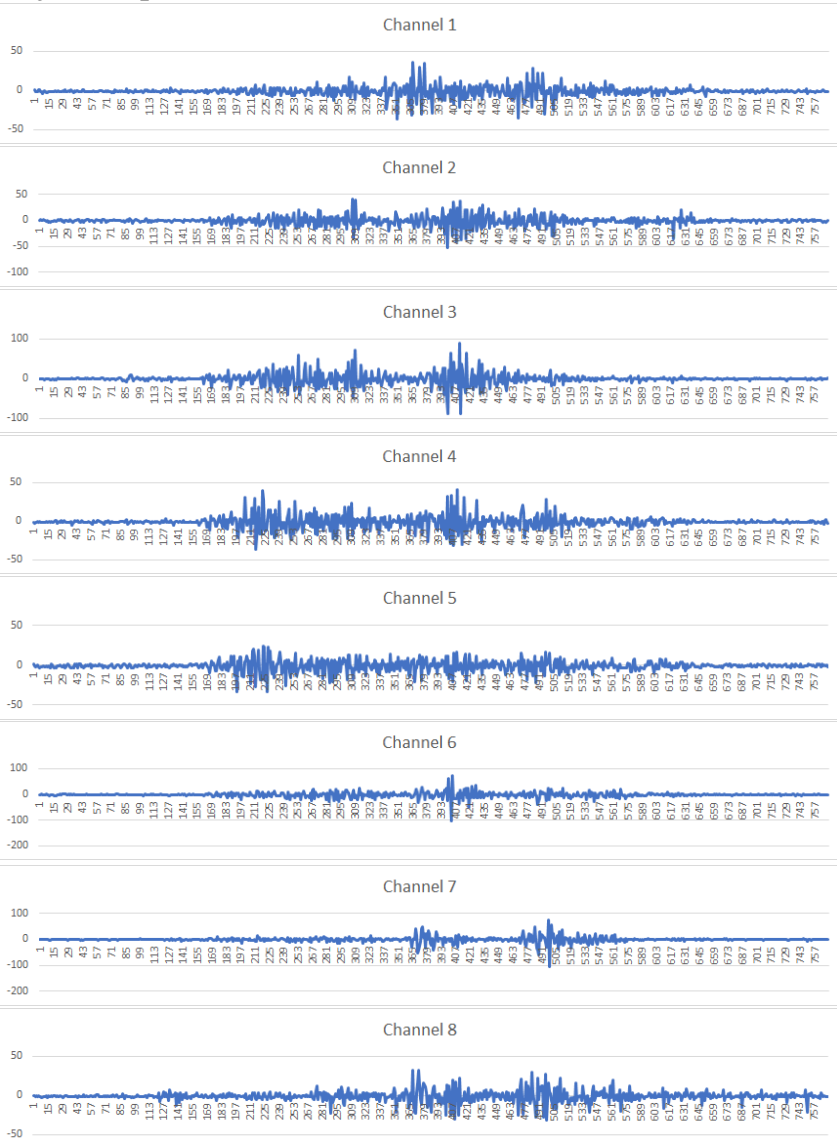

Gambar 5. visualisasi sinyal RAW EMG setiap channel

\section{B. Pre-Processing}

Data raw hasil perekaman sinyal EMG mengandung nilai positif dan negatif. Oleh karena itu, nilai-nilai negatif perlu diabsolutkan agar jangkauan pembacaan data tidak telalu melebar [1]. Absolut adalah langkah mengubah nilai negatif pada sinyal EMG menjadi positif karena sinyal yang memiliki nilai negatif tidak dapat dilakukan perhitungan. Selain itu, pada persamaan matematika metode ekstraksi time domain menggunakan nilai yang sudah dimutlakkan.

Untuk membersihkan noise rendah yang masih ikut dalam pembacaan data diperlukan sebuah pengaturan ambang batas (threshold). Nilai threshold juga dapat digunakan untuk mendeteksi mulai dan berakhirnya gerakan. Pada penelitian ini nilai threshold yang digunakan adalah $20 \mu \mathrm{V}$. Sinyal yang memiliki nilai dibawah $20 \mu \mathrm{V}$ akan diubah menjadi 0 . Nilainilai inilah yang akan dihitung nilai fiturnya. 


\section{Ekstraksi Fitur}

Sinyal EMG mentah yang diakuisisi dari sejumlah elektrode yang diposisikan pada otot mengandung sejumlah besar data dan masih memiliki sedikit informasi. Jika data mentah EMG ini digunakan sebagai masukan dalam proses klasifikasi, maka akurasi klasifikasi akan menjadi rendah dan waktu kalkulasi akan meningkat. Sehingga sebelum memasuki pengenalan pola, data mentah EMG membutuhkan transformasi fitur-fitur yang representatif.

Metode yang digunakan untuk ekstraksi fitur adalah time domain series, yaitu berdasarkan nilai MAV, RMS, VAR, dan SSI. Dalam satu waktu yang sama myo armband menghasilkan delapan sinyal dari ke-8 channel sensor EMG. Dari ke-delapan sinyal EMG tersebut akan dikenai masing-masing 4 fitur. Sehingga keluaran yang dihasilkan sebanyak 32 fitur untuk sinyal EMG. Dengan kata lain, satu data gerakan memiliki 32 fitur.

\section{Klasifikasi}

Metode klasifikasi pada penelitian ini adalah menggunakan metode nä̈ve bayes. Naive Bayes Classifier bersifat supervised learning yang membutuhkan data learning sebagai representasi. Oleh karena itu, data yang sudah dikelompokkan pada ekstraksi fitur akan dipisah berdasarkan perannya yaitu sebagai data training dan data testing. Data training digunakan sebagai representasi pengetahuan yang akan digunakan untuk memprediksi kelas data baru yang belum pernah ada. Data testing digunakan untuk mengukur sejauh mana classifier berhasil melakukan klasifikasi yang benar. Pada data training ditambahkan ground truth untuk masing-masing kelas. Ground truth merupakan label penomoran yang digunakan untuk membedakan setiap kelas gerakan.

Klasifikasi yang digunakan pada penelitian ini adalah menggunakan klasifikasi naive bayes karena algoritmanya yang sederhana, cepat dan memiliki akurasi yang tinggi. Langkah-langkah pengklasifikasian menggunakan metode nave bayes terdiri atas:

1. Perhitungan nilai parameter

Algoritma Gaussian membutuhkan dua parameter, yakni nilai rata-rata (mean) kelas dan juga nilai varian kelas. Dimisalkan nilai mean adalah $\mu \mathrm{c}$ dan nilai standar deviasi adalah $\sigma_{\mathrm{c}}$ sehingga nilai varian adalah $\sigma_{\mathrm{c}}{ }^{2}$. Standar deviasi atau varian digunakan untuk mengetahui keragaman pada suatu kelompok data

2. Perhitungan Gaussian

Setelah nilai varian diketahui, selanjutnya adalah menghitung nilai probabilitas kelas $\mathrm{C}$ dengan data baru $v$ (data testing) atau $P(x=v \mid C)$ menggunakan rumus perhitungan Gaussian yang secara detail dijelaskan pada BAB 2. Selanjutnya melakukan perhitungan prior (prior probability) untuk mendapatkan nilai probabilitas antar kelas.

3. Prediksi Kelas

Dikarenakan dalam hal ini data bersifat multiclass maka selanjutnya dipilih nilai arg max (arguments of maxima) dari perkalian hasil probabilitas dari masing-masing kelas.
Nilai terbesar dari perhitungan tersebut merupakan hasil prediksi kelas.

\section{PENGUJIAN SISTEM KLASIFIKASI}

Pada penelitian ini pengujian gerakan bahasa isyarat dilakukan dengan menghitung tingkat akurasi yang dapat dilihat pada persamaan (9).

$$
\text { Akurasi }=\frac{\text { Jumlah Gerakan Benar }}{\text { Total Gerakan }} \times 100 \%
$$

Sebelum dilakukan pengujian akan dilakukan pengklasifikasian yang bertujuan untuk mengetahui apakah sistem sudah memiliki kemampuan generalisasi yang baik dalam mengklasifikasikan data. Data masukan yang berupa fitur-fitur dipisahkan menurut perannya, yaitu sebagai data training dan data testing. Perbandingan jumlah data yang digunakan untuk pengklasifikasian ini adalah 50:50 atau 50\% data akan dijadikan sebagai data training dan 50\% data akan dijadikan data testing. Pada pengklasifikasian pertama, data training akan digunakan sebagai data learning atau dataset pembanding dan sebagai data uji sekaligus. Sedangkan pada pengklasifikasian kedua data learning akan diuji menggunakan data baru yang tidak ada di dalam dataset pembanding. Hasil klasifikasi dapat dilihat pada Gambar 6.

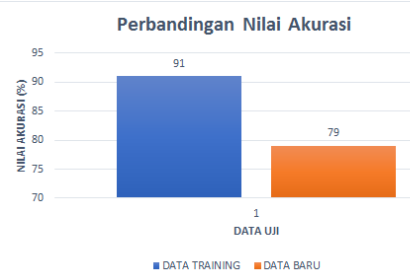

Gambar 6. Perbandingan hasil akurasi data training yang diujikan dengan trained data dan untrained data

Gambar 6 merupakan perbandingan hasil akurasi dari klasifikasi data training yang diujikan menggunakan data training dan hasil akurasi data training yang diujikan menggunakan data baru. Nilai akurasi yang didapat dalam pengklasifikasian data training yang diujikan menggunakan data training lebih besar dibandingkan dengan hasil akurasi pada pengklasifikasian data training yang diujikan menggunakan data baru yaitu sebesar 91\% dibandingkan dengan 79\%. Hal ini dapat terjadi karena data uji yang digunakan pada pengklasifikasian pertama sudah ada di dalam dataset pembanding, sistem digunakan untuk mengenali dirinya sendiri sehingga kemungkinan dikenali benar sangatlah besar. Sistem memiliki kemampuan generalisasi yang baik dalam melakukan klasifikasi data sehingga menghasilkan akurasi yang cukup besar pada kedua pengklasifikasian, yaitu $91 \%$ dan $79 \%$

Dari pengklasifikasian sebelumnya, sistem sudah memiliki kemampuan generaliasasi yang baik, untuk menguji kemampuan sistem maka dilakukan sebuah pengujian. Adapun pengujian yang dilakukan pada penelitian ini adalah sebagai berikut:

1. Pengujian terhadap perbandingan jumlah data training dan data testing 
Pengujian menggunakan perbandingan jumlah data training dan data testing yang bertujuan untuk mengetahui jumlah perbandingan yang ideal untuk digunakan pada proses klasifikasi. Dari total 400 data sampel, dibagi menjadi data training dan data testing seperti pada Tabel 1. Jumlah sampel pada setiap kelas gerakan memiliki jumlah yang sama. Jadi, misalkan pada data training yang digunakan adalah 40 sampel, maka dari 20 gerakan isyarat kata masing-masing memiliki 2 sampel pada data training.

Tabel 1 .

Perbandingan jumlah data training dan testing

\begin{tabular}{ccc}
\hline \hline \multirow{2}{*}{ Percobaan } & \multicolumn{2}{c}{ Jumlah Data } \\
\cline { 2 - 3 } & Training & Testing \\
\hline 1 & 40 & 360 \\
2 & 80 & 320 \\
3 & 120 & 280 \\
4 & 160 & 240 \\
5 & 200 & 200 \\
6 & 240 & 260 \\
7 & 280 & 120 \\
8 & 320 & 80 \\
9 & 360 & 40 \\
\hline \hline
\end{tabular}

Sistem dilakukan proses pengenalan terhadap data training yang berjumlah 40 data dengan data uji berjumlah 360 data. Kemudian dilakukan pencatatan hasil akurasi. Selanjutnya sistem digunakan untuk mengenali data training yang berjumlah 80 data dengan data uji berjumlah 320 data. Proses pengklasifikasian dilakukan hingga jumlah sampel data training 360 sampel. Tingkat keberhasilan dari setiap percobaan dapat dilihat pada Gambar 7 .

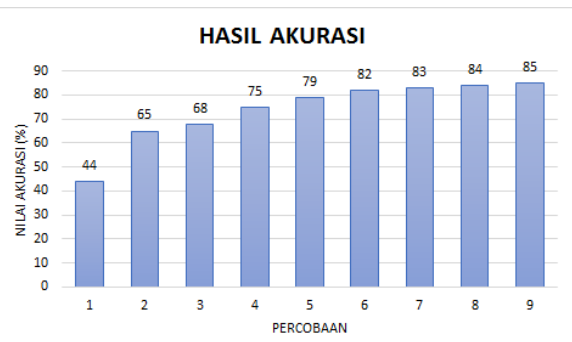

Gambar 7. Hasil akurasi terhadap perbandingan jumlah data training dandata testing

Hasil akurasi dari setiap pengklasifikasian dapat diamati pada Gambar 7. Pada pengklasifikasian menggunakan data training berjumlah 40 sampel memiliki akurasi yang paling rendah, yaitu 44\%. Data pada data training tersebut memiliki 2 sampel setiap kelasnya. Sehingga, hanya ada 2 variasi data pada setiap kelas data. Akurasi paling besar diperoleh pada saat jumlah data training 360 sampel, yaitu sebesar 85\%. Jumlah sampel masing-masing kelas sebanyak 18 sampel. Sehingga ada 18 variasi data yang dimiliki pada masing-masing kelas data.

Besar akurasi terus meningkat secara signifikan mulai dari data training berjumlah 40 sampel hingga 200 sampel. Selanjutnya akurasi meningkat secara konstan yaitu sebesar $1 \%$ pada setiap percobaan. Pada percobaan tersebut akurasi telah mencapai tingkat yang optimal dimana akurasi yang diperoleh tidak mengalami peningkatan yang signifikan, yaitu pada data training yang jumlahnya lebih besar dibandigkan dengan jumlah data testing. Dapat disimpulkan bahwa semakin banyak variasi data, maka tingkat akurasi juga semakin meningkat. Jumlah data training harus lebih besar jika dibandingkan dengan jumlah data testing hal ini dikarenakan fungsi dari data training adalah sebagai representasi pengetahuan yang akan digunakan untuk memprediksi kelas data baru yang belum pernah ada.

\section{Pengujian terhadap pengaruh fitur}

Berdasarkan hasil pengklasifikasian sebelumnya pada perbandingan jumlah data training dan data testing sebesar 60:40 atau pada data training berjumlah 240 dan data testing berjumlah 160, yang menggunakan empat fitur, yaitu MAV, RMS, VAR dan SSI menghasilkan akurasi sebesar $82 \%$. Hasil dari klasifikasi menggunakan empat fitur tersebut akan dibandingkan dengan hasil klasifikasi menggunakan jumlah perbandingan data yang sama dan dengan fitur yang kurang dari empat buah fitur. Pengujian ini bertujuan untuk melihat pengaruh fitur terhadap hasil klasifikasi menggunakan metode naive bayes. Dari keempat fitur tersebut akan dilihat fitur manakah yang dapat meningkatkan atau menurunkan akurasi. Pada percobaan pertama, klasifikasi dilakukan dengan menghilangkan salah satu fitur kemudian dilihat pengaruh fitur tersebut terhadap hasil akurasi. Pada percobaan kedua, klasifikasi dilakukan dengan menghilangkan dua buah fitur. Selanjutnya pada percobaan ketiga, klasifikasi dilakukan menggunakan sebuah fitur saja. Kemudian hasil akurasi akan dibandingkan dengan hasil akurasi menggunakan empat fitur tersebut. Hasil dari pengujian tersebut ditampilkan pada Tabel 2, Tabel 3 dan Tabel 4.

Tabel 2.

Hasil akurasi menggunakan 3 fitur

\begin{tabular}{ccccc}
\hline \hline Percobaan & \multicolumn{3}{c}{ Parameter } & Akuras1 (\%) \\
\hline 1 & MAV & RMS & VAR & 84 \\
2 & MAV & RMS & SSI & 81 \\
3 & MAV & VAR & SSI & 82 \\
4 & RMS & VAR & SSI & 82 \\
\hline \hline
\end{tabular}

Tabel 2 merupakan hasil akurasi pengklasifikasian menggunakan tiga buah fitur. Pada pengklasifikasian menggunakan tiga fitur diperoleh hasil akurasi tertinggidengan menggunakan fitur MAV, RMS dan VAR, yaitu sebesar $84 \%$. Hasil akurasi ini lebih tinggi jika dibandingkan dengan hasil akurasi menggunakan 4 fitur yang mempunyai akurasi sebesar 82\%. Dapat disimpulkan bahwa penghilangan fitur SSI dapat meningkatkan akurasi. Parameter MAV dan RMS tidak memiliki pengaruh besar terhadap klasifikasi. Parameter yang memiliki pengaruh terbesar adalah fitur VAR yaitu sebesar $1.0 \%$ yang apabila fitur ini dihilangkan dapat mengakibatkan penurunan akurasi.

Tabel 3 .

Hasil akurasi menggunakan 2 fitur

\begin{tabular}{|c|c|c|c|}
\hline Percobaan & \multicolumn{2}{|c|}{ Parameter } & 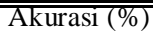 \\
\hline$T$ & MAV & RMS & 84 \\
\hline 2 & MAV & VAR & 85 \\
\hline 3 & MAV & SSI & 80 \\
\hline 4 & RMS & VAR & 83 \\
\hline 5 & RMS & SSI & 81 \\
\hline 6 & VAR & SSI & 82 \\
\hline
\end{tabular}

Tabel 3 merupakan hasil akurasi pengklasifikasian menggunakan dua buah fitur. Pada pengklasifikasian menggunakan dua buah fitur diperoleh hasil akurasi tertinggi 
dengan menggunakan fitur MAV dan VAR, yaitu sebesar $85 \%$. Hasil akurasi ini lebih tinggi jika dibandingkan dengan hasil akurasi menggunakan 4 fitur yang mempunyai akurasi sebesar $82 \%$. Dari percobaan 1 sampai 6 dapat diketahui bahwa penggunaan fitur SSI pada semua percobaan rata-rata mengalami penurunan akurasi. Sedangkan penggunaan fitur VAR pada semua percobaan rata-rata dapat meningkatkan akurasi. Dapat disimpulkan bahwa parameter yang memiliki pengaruh terbesar dalam peningkatan akurasi adalah fitur VAR. Penghilangan fitur VAR berakibat pada penurunan akurasi.

Tabel 4.

Hasil akurasi menggunakan 2 fitur

\begin{tabular}{ccc}
\hline \hline Percobaan & Parameter & Akuras1(\%) \\
\hline 1 & MAV & 81 \\
2 & RMS & 84 \\
3 & VAR & 82 \\
4 & SSI & 80 \\
\hline \hline
\end{tabular}

Tabel $\overline{\overline{4} \text { merupakan hasil akurasi klasifikasi }}$ dengan menggunakan sebuah fitur. Pada percobaan pertama, dilakukan pengklasifikasian menggunakan fitur MAV diperoleh hasil akurasi sebesar $81 \%$. Pada percobaan kedua, dilakukan pengklasifikasian menggunakan fitur RMS diperoleh hasil akurasi sebesar 84\%. Pada percobaan ketiga, dilakukan pengklasifikasian menggunakan fitur VAR diperoleh hasil akurasi sebesar 82\%. Pada percobaan keempat, dilakukan pengklasifikasian menggunakan fitur SSI diperoleh hasil akurasi sebesar $80 \%$. Urutan tingkat akurasi mulai dari yang terbesar hingga terkecil adalah pada fitur RMS, VAR, MAV dan SSI yaitu sebesar $84 \%, 82 \%, 81 \%$ dan $80 \%$. Sistem yang dilakukan proses pengklasifikasian menggunakan sebuah fitur saja sudah cukup tinggi. Dari pengklasifikasian menggunakan sebuah fitur, dua buah fitur dan tiga buah fitur dapat diambil kesimpulan bahwa penghilangan fitur tidak memberikan pengaruh yang besar terhadap hasil akurasi.

\section{KESIMPULAN}

Berdasarkan analisis dan pembahasan pada bab sebelumnya, diperoleh kesimpuan sebagai berikut:
1. Pengklasifikasian data training yang diujikan dengan data training memiliki kemungkinan dikenali yang lebih besar yaitu dengan akurasi 91\% dibandingkan dengan hasil akurasi dari pengklasifikasian data training yang diujikan dengan data baru yaitu sebesar $79 \%$.

2. Jumlah perbandingan data training yang optimal digunakan untuk klasifikasi adalah $\geq 50 \%$ dari total data sampel karena menunjukkan nilai akurasi yang lebih baik dimana berada pada rata-rata $80 \%$.

3. Pada pengklalsifikasian menggunakan tiga buah fitur, diperoleh tingkat keberhasilan paling tinggi yaitu pada fitur MAV, RMS dan VAR sebesar $84 \%$ dan tingkat keberhasilan paling rendah yaitu pada fitur MAV, RMS dan SSI sebesar $81 \%$.

4. Pada pengklasifikasian menggunakan dua fitur diperoleh hasil akurasi tertinggi dengan menggunakan fitur MAV dan VAR, yaitu sebesar $85 \%$ dan hasil akurasi terendah dengan menggunakan fitur MAV dan SSI, yaitu sebesar $80 \%$.

5. Hasil akurasi dari pengklasifikasian menggunakan sebuah fitur saja sudah cukup tinggi, yaitu diatas $80 \%$. Urutan tingkat keberhasilan mulai dari yang terbesar hingga terkecil adalah pada fitur RMS, VAR, MAV, dan SSI, yaitu sebesar $84 \%, 82 \%, 81 \%$ dan $80 \%$.

\section{DAFTAR PUSTAKA}

[1] and V. T. J. G. Abreu, J. M. Teixeira, L. S. Figueiredo, "Evaluating sign language recognition using the myo armband," in XVIII Symposium on Virtual and Augmented Reality (SVR),2016,pp.64 70.

[2] G. P.-J. and J. H. Terriza, "Hand gesture recognition basedonsemg signals using support vector machines," IEEE 6th Int.Conf.Consum. Electron. Berlin, pp. 174-178, 2016.

[3] and M. A. M. Irfan, W. Caesarendra, "Studi klasifikasi tujuh gerakan tangan sinyal electromyography (emg) menggunakan metode pattern recognition," J. Tek. Mesin S-1 Undip, vol.4,no.3, pp. 307-316, 2016. 